\title{
Artificial intelligence for physical agents
}

Published online: 4 February 2022

(C) Springer Science+Business Media, LLC, part of Springer Nature 2022

Multimedia Tools and Applications gratefully acknowledges the editorial work of the scholars listed below on the special issue entitled "Artificial Intelligence for Physical Agents" (SI 1188). This special issue is based on the 21st International Workshop of Physical Agents (WAF 2020), November 19-20, 2020, Alcalá de Henares, Madrid, Spain.

Of 22 papers submitted, 15 were accepted for this issue after a stringent peer review process.

\section{Corresponding Guest Editor}

\section{Luis M. Bergasa}

University of Alcalá, Madrid, Spain

Email: luism.bergasa@uah.es

\section{Guest Editors}

\section{Manuel Ocaña}

University of Alcalá, Madrid, Spain

Email: manuel.ocanna@uah.es

\section{Rafael Barea}

University of Alcalá, Madrid, Spain

Email: rafael.barea@uah.es

Publisher's note Springer Nature remains neutral with regard to jurisdictional claims in published maps and institutional affiliations. 